\title{
A Preliminary Study on Ecotourism Development of Wuling Gorge Geological Park, Zhushan County, Hubei Province--Based on RMP Analysis
}

\author{
Zhiwu Yan, Hongmei Wang, Yao Wang, Qingrong Ran \\ China University of Geosciences, No.388 of Lumo Road, Whuan, 43000, China \\ yanzw11@163.com
}

Keywords: RMP analysis; Geopark ; Eco-tourism development

Abstract. Wuling Gorge area in Zhushan county, Hubei province, is a typical karst distribution in western Hubei and it is part of "Western Hubei ecological and cultural tourism circle". In order to protect the fragile karst ecosystem, and achieve a reasonable development of local ecotourism, the authors in this paper choose Wuling Gorge Geological Park as a study area. Based on RMP analysis theory, after a thorough literature review, the authors analyze and summarize relative studies, then adopt qualitative and quantitative evaluation method. Then, $\mathrm{R}$ analysis is adopted to evaluate the ecotourism resources in Wuling Gorge geological Park. And SWOT analysis is conducted to have a $\mathrm{P}$ analysis for tourism product development, which tells the strengths, weaknesses, opportunities and threats of the tourism products. With the help of the above analyses, the authors propose to develop the Wuling Gorge Geopark ecological tourism and suggest measures to guarantee the development. Thus, the authors not only provide an important theoretical reference for the development, planning and designing of this area, but also may guarantee the local sustainable tourism development by healthy interaction between geopark tourism and eco-environment.

\section{基于 RMP 分析的湖北竹山武陵峡地质公园 生态旅游开发的初步探讨}

\author{
鄢志武，王红梅，王圭，再清蓉 \\ 中国地质大学 (武汉), 湖北, 中国 \\ yanzw11@163.com
}

关键词: RMP分析;地质公园; 生态旅游开发

中文摘要. 湖北竹山武陵峡地区是鄂西典型的喀斯特地貌分布区, 也是 “鄂西生态文化旅游 圈” 的组成部分。为保护该区脆弱的喀斯特生态系统, 实现当地生态旅游的合理开发, 本文 选取武陵峡地质公园为例, 引入RMP分析理论, 通过对国内外相关文献的研究、归纳和总结, 运用定性与定量评价相结合的方法对竹山武陵峡地质公园喀斯特生态旅游资源进行 $\mathrm{R}$ 分析, 明确资源的开发价值, 运用SWOT分析法对武陵峡地质公园生态旅游产品开发进行P分析, 得 出生态旅游产品开发具有的优势、劣势、机遇和威胁，在对此公园的系统分析基础上提出武 陵峡地质公园生态旅游开发的构想和保障措施, 从而为该地质公园旅游业的开发、规划与布 局提供重要的理论参考, 实现地质公园旅游业与生态环境的良性互动, 确保当地旅游业的可 持续发展。

\section{1. 湖北竹山武陵峡地质公园区域地质概况与旅游地学资源评价}

\section{1 地层分布与地质构造}

地层是地质历史上某一时代形成的层状岩石，它可以是某种固结的岩石体，也可以是没 有固结的堆积物。从岩性上讲, 地层包括各种沉积岩、火山岩和变质岩; 从时代上讲, 地层 有老有新, 具有一定的时间概念, 竹山武陵峡地质公园内出露的地层从老到新有: 新元古界 
震旦系、古生界寒武系、奥陶系和志留系、二叠系，中生界三叠系等。竹山武陵峡地质公园 为我国第二阶梯和第三阶梯的结合边缘, 在地质构造上属于新生代以来大幅度隆升的地区, 地跨扬子准地台一级大地构造单元。

公园内部为以近东西向的弧形挤压带为主体，还出现北东、北西线两组断层，它们均分 布于官渡镇的东西两侧, 这两组断层在在切断了近东西向构造同时, 又在近东西向构造线内 形成一些次级小褶曲。它北部是一个密集线行的挤压带, 由一系列密集背斜、向斜和冲断组 成, 很难找到一个完整的褶皱, 一般是仰冲于南盘之上，使上盘产生拖拽，下盘产生倒转， 紧接着前方出现一个北冲的冲断带，二者组成对冲形式，反应了南北向侧压力的存在。

本区的中部和南部，发育有规模较大的近东西向的挤压带，其主要由寒武系碳酸盐岩石 组成的向斜背斜及断层等构造行迹所组成，在这种特殊的地质构造背景下，也形成了独特的 地质遗迹景观, 如地处本区南部的天台洞, 该洞穴发育在寒武系下统的地层上, 洞穴岩石层 为炭质灰岩和薄层泥质灰岩, 洞口围岩产状约为 $183^{\circ} \angle 76^{\circ}-80^{\circ}$, 在该洞内发现了世界上 最长的鹅管。

\section{2 竹山武陵峡地质公园生态旅游资源分析 $(\mathrm{R})$}

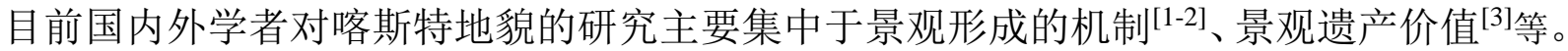
本文从喀斯特生态旅游资源条件、生态环境、生态旅游开发条件三方面方面入手, 依据 RMP 分析理论 ${ }^{[4]}$, 探索性的构造了武陵峡喀斯特地质公园生态旅游资源的评价指标体系, 其中, 喀斯特生态旅游资源综合评价是总目标层（A），生态旅游资源条件、生态环境条件、生态 旅游开发条件为第二层综合评价层（B），喀斯特特征典型性、喀斯特资源奇特性、喀斯特 资源聚集度、喀斯特资源优美度、喀斯特资源丰度与规模、喀斯特资源空间组合、喀斯特资 源科研价值、历史文化价值、生态休闲价值、大气与水体质量、植被覆盖指数、生态环境容 量、地理区位条件、旅游交通条件、基础服务设施、市场开发潜力、社会经济发展水平等 18 项指标因子作为第三层评价因子层（C），以此建立喀斯特地质公园生态旅游资源总目标评 价模型树（见图 1)。

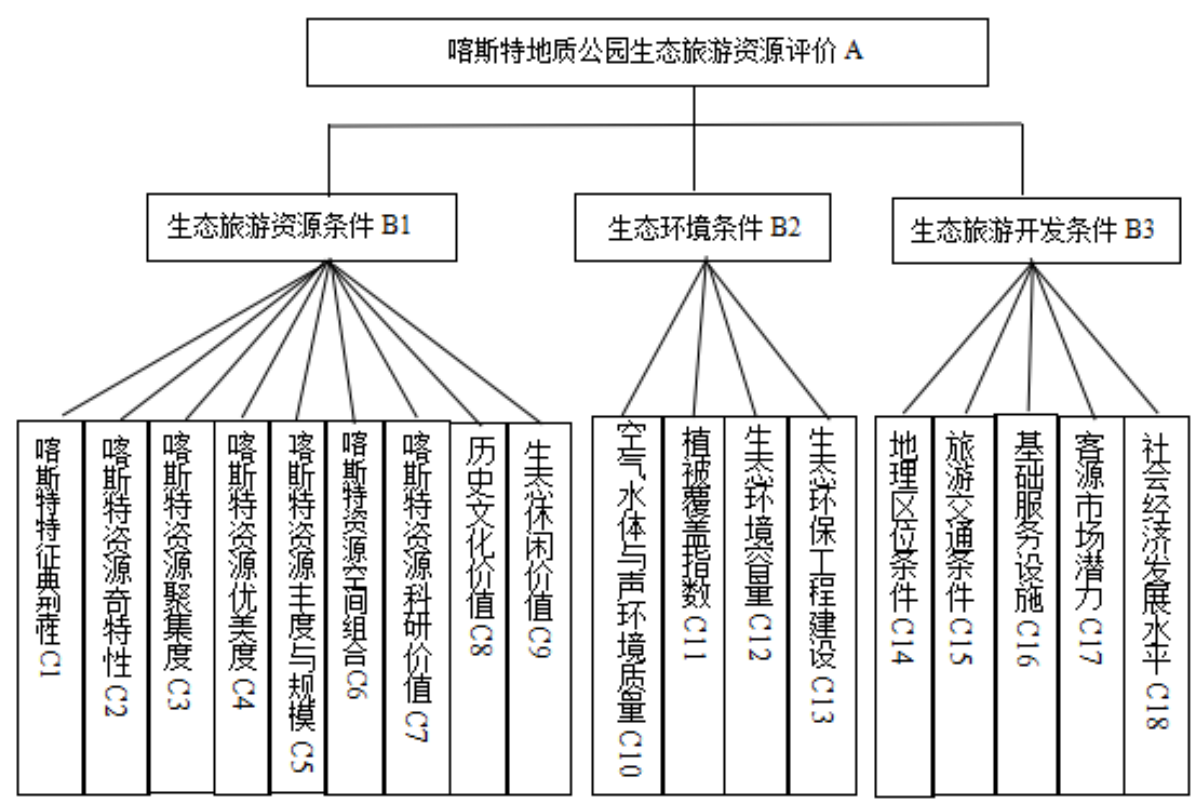

图 1 喀斯特地质公园生态旅游资源评价模型树

结合地质公园的具体情况, 用表格的形式设计问卷, 运用德尔菲法给对竹山武陵峡地质 公园比较熟悉的 10 位不同专业背景的专家及相关人员 (包括地质公园管理者、生态旅游爱好 者、旅游地学、岩溶学、生态学等方面的专家) 发放调查表, 恳请他们按照同等重要、稍微 重要、明显重要、强烈重要、极端重要的判别级别, 以 1、3、5、7、9 或其倒数作为量化标 准，2、4、6、8 表示两相邻判断中值的标准进行判断, 获得同一层次中的各因素相对于上一 
层的各项因子相对重要性的判断矩阵的取值（表 1)，最后运用 Yaahp10.3 软件逐层确定各因 子指标的相对权重（ $\mathrm{W}_{\mathrm{i}} ） （$ 表 2)，并对结果进行一致性检验。

表 1 比较标度及其含义

\begin{tabular}{|c|l|}
\hline 标度 & \multicolumn{1}{|c|}{ 含义 } \\
\hline 1 & 两个因素相比较, 具有相同重要性 \\
\hline 3 & 两个因素相比较, 一个比另一个稍微重要 \\
\hline 5 & 两个因素相比较, 一个比另一个明显重要 \\
\hline 7 & 两个因素相比较, 一个比另一个强烈重要 \\
\hline 9 & 两个因素相比较, 一个比另一个极端重要 \\
\hline $2,4,6,8$ & 上述两相邻判断中值 \\
\hline 倒数 & $\begin{array}{l}\text { 如果因素 } \mathrm{i} \text { 与 } \mathrm{j} \text { 相比较得判断 } \mathrm{Bij}, \text { 则因素 } \mathrm{j} \text { 与 } \mathrm{i} \text { 的判断为 } \\
\text { Bij=1/Bij, }\end{array}$ \\
\hline
\end{tabular}

表 2 各评价指标相对权重的判断

\begin{tabular}{|l|l|l|l|l|l|}
\hline 目标层 & $\begin{array}{l}\text { 综合评 } \\
\text { 价层 }\end{array}$ & $\begin{array}{c}\text { 一级权重 } \\
\mathrm{W}\end{array}$ & \multicolumn{1}{|c|}{ 评价因子层 } & \multicolumn{1}{|c|}{ 二评价内容 } \\
Wi
\end{tabular}

依据评价模型树和综合评价指标体系表，将综合评价层和评价因子层各指标的等级分为 优秀、良好、一般、较差四个评价等级, 即评语集合为: $V=\left\{V_{1}, V_{2}, V_{3}, V_{4}\right\}=\{$ 优秀, 良好, 一般，较差 $\}$ ，分别赋予评语集优秀、良好、一般、较差不同的含义:

优秀:生态旅游资源开发价值很高,应当进行旅游开发;

良好:生态旅游资源有一定开发价值,适合旅游开发; 
一般:生态旅游资源开发价值一般,旅游开发处于适合与不适合的中间状态;

较差:生态旅游资源没有开发价值,不适合旅游开发;

邀请专家评判小组共十人, 每一个成员根据已经确定的评价等级标准依次对武陵峡地质 公园生态旅游资源各个指标进行评价, 来确定各个单因子的隶属度 $\mathrm{R}_{\mathrm{ij}}$ (见表 3), 然后做统计处 理。假设 $\mathrm{X}_{\mathrm{ij}}(\mathrm{i}=1,2 \ldots \mathrm{m})$ 是评定第 $\mathrm{i}$ 项因素、第 $\mathrm{j}$ 等级的人数, 按照公式

$$
R_{i j}=X_{i j} / \sum_{j=1}^{m}(i=1,2, \ldots n)
$$

即可计算出 $R_{i j}$ 的值, 联合各单因子评价值组成的向量, 可得到相应的模糊评价矩 $R$ $(\mathrm{i}=1,2,3)$ 。

$$
R_{i}=\left[\begin{array}{cccc}
R_{11} & R_{12} & \ldots & R_{1 m} \\
R_{21} & R_{22} & \ldots & R_{2 m} \\
\ldots & \ldots & \ldots & \ldots \\
R_{n 1} & R_{n 2} & \ldots & R_{n m}
\end{array}\right]
$$

由表 1 可以得出个各单因子的模糊决策矩阵 $\mathrm{R}_{1}, \mathrm{R}_{2}, \mathrm{R}_{3}$,

$$
R_{1}=\left[\begin{array}{cccc}
0.3 & 0.5 & 0.2 & 0 \\
0.5 & 0.5 & 0 & 0 \\
0.3 & 0.4 & 0.3 & 0 \\
0.6 & 0.4 & 0 & 0 \\
0.6 & 0.2 & 0.2 & 0 \\
0.5 & 0.4 & 0.1 & 0 \\
0.6 & 0.4 & 0 & 0 \\
0.4 & 0.4 & 0.2 & 0 \\
0.5 & 0.5 & 0 & 0
\end{array}\right]
$$$$
R_{2}=\left[\begin{array}{cccc}
0.8 & 0.2 & 0 & 0 \\
0.7 & 0.3 & 0 & 0 \\
0.4 & 0.5 & 0.1 & 0 \\
0.2 & 0.5 & 0.3 & 0
\end{array}\right]
$$

\begin{tabular}{|c|c|c|c|c|c|c|c|}
\hline 评价因子层 & & $\begin{array}{c}\text { 二级权重 } \\
\text { (Wi) }\end{array}$ & \multirow{10}{*}{$\mathrm{R} 1$} & 好 $\mathrm{V}_{1}$ & 较好 $\mathrm{V}_{2}$ & 一般 $V_{3}$ & 较差 $\mathrm{V}_{4}$ \\
\hline 喀斯特特征典型性(C1) & \multirow{9}{*}{ W1 } & 0.1071 & & 0.3 & 0.5 & 0.2 & 0 \\
\hline 喀斯特资源奇特性(C2) & & 0.2174 & & 0.5 & 0.5 & 0 & 0 \\
\hline 喀斯特资源聚集度(C3) & & 0.0964 & & 0.3 & 0.4 & 0.3 & 0 \\
\hline 喀斯特资源优美度(C4) & & 0.1620 & & 0.6 & 0.4 & 0 & 0 \\
\hline 喀斯特资源丰度与规模(C5) & & 0.1158 & & 0.6 & 0.2 & 0.2 & 0 \\
\hline 喀斯特资源空间组合(C6) & & 0.0673 & & 0.5 & 0.4 & 0.1 & 0 \\
\hline 喀斯特资源科学价值(C7) & & 0.0575 & & 0.6 & 0.4 & 0 & 0 \\
\hline 历史文化价值(C8) & & 0.0470 & & 0.4 & 0.4 & 0.2 & 0 \\
\hline 生态休闲价值(C9) & & 0.1294 & & 0.5 & 0.5 & 0 & 0 \\
\hline 空气水体与声环境(C10) & \multirow{4}{*}{ W2 } & 0.2762 & \multirow{4}{*}{$\mathrm{R} 2$} & 0.8 & 0.2 & 0 & 0 \\
\hline 植被覆盖指数(C11) & & 0.2988 & & 0.7 & 0.3 & 0 & 0 \\
\hline 生态环境容量(C12) & & 0.2113 & & 0.4 & 0.5 & 0.1 & 0 \\
\hline 生态环保工程建设(C13) & & 0.2138 & & 0.2 & 0.5 & 0.3 & 0 \\
\hline 地理区位条件(C14) & \multirow{5}{*}{ W3 } & 0.1406 & \multirow{5}{*}{ R3 } & 0.1 & 0.1 & 0.4 & 0.4 \\
\hline 旅游交通条件(C15) & & 0.5444 & & 0 & 0 & 0.2 & 0.8 \\
\hline 基础服务设施(16) & & 0.1546 & & 0 & 0 & 0.3 & 0.7 \\
\hline 客源市场潜力(C17) & & 0.1158 & & 0 & 0.3 & 0.4 & 0.3 \\
\hline 社会经济发展水平(C18) & & 0.0419 & & 0 & 0 & 0.4 & 0.6 \\
\hline
\end{tabular}$$
R_{3}=\left[\begin{array}{cccc}
0.1 & 0.1 & 0.4 & 0.4 \\
0 & 0 & 0.2 & 0.8 \\
0 & 0 & 0.3 & 0.7 \\
0 & 0.3 & 0.4 & 0.3 \\
0 & 0 & 0.4 & 0.6
\end{array}\right]
$$ 
根据评判矩阵和对应的二级权重系数向量 $\mathrm{W}_{\mathrm{i}}$, 基于模糊变换原理, 运用 MATLAB7.0 软 件经过合成运算（采用普通矩阵乘法进行合成）得到一级模糊综合评价结果 $\mathrm{Bi}\left(\mathrm{Bi}=\mathrm{W}_{\mathrm{i}} \times \mathrm{R}_{\mathrm{i}}\right.$, 其中 $\mathrm{i}=1 ， 2 ， 3$ )的三个单因素模糊综合评价 B1，B2，B3，
$\mathrm{B} 1=(0.48808$
0.42219
0.08963
$0)$
$\mathrm{B} 2=(0.5574$
0.35743
0.08527
$0.04226)$

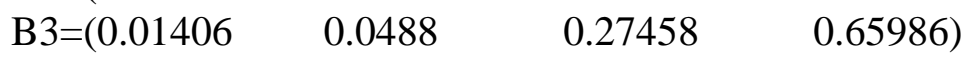

基于一级模糊综合评判结果，由三个单因素综合评价结果共同组成二级模糊综合评判矩 阵 $\mathrm{R}$

再由 $\mathrm{A}$ 的各子

$$
R=\left[\begin{array}{cccc}
0.48808 & 0.42219 & 0.08963 & 0 \\
0.5574 & 0.35743 & 0.08527 & 0.04226 \\
0.01406 & 0.0488 & 0.27458 & 0.65986
\end{array}\right]
$$

集组成的一级权重系数向量 $\mathrm{W}$ 和 二级模糊综合评价矩阵 $\mathrm{R}$, 经过合成运算，得出武陵峡地质公园的生态旅游资源二级模糊综 合评价结果

$$
\mathrm{A}=\mathrm{W} \times \mathrm{R}=\left(\begin{array}{llll}
0.4754 & 0.37826 & 0.1036 & 0.0636
\end{array}\right)
$$

从一级模糊综合评价结果可看出, 按最大隶属度原则, 武陵峡地质公园生态旅游资源条 件和生态环境条件都隶属于 “好” 的等级, 而生态旅游开发条件属于 “较差” 等级, 从二级 模糊综合评价的结果看, 武陵峡地质公园生态旅游资源总体状况趋向于隶属评价等级中的优 秀和良好两级，总分值为 $0.8537 ，$ 开发潜力大，非常适合进行生态生态旅游开发。

在该评价中，生态旅游资源（B1）权重较大，达到了 0.6438 , 说明地质公园的生态旅游 资源具有很高的开发价值，是开展生态旅游的基本前提条件。其中资源的奇特性（C2）权重 为 0.2174 在 $\mathrm{B} 1$ 层次九个因子中最高, 这在天台溶洞世界最长鹅管这一景点中凸显出来了。 资源优美度 (C4) 和生态休闲价值（C9）权重分别位于第二位和第三位, 这说明武陵峡地质 公园生态旅游的开发应以观赏游览和生态休闲产品为主。生态环境条件（B2）在综合评价层 中排名居中，植被覆盖指数(C11)和空气水体与声环境质量(C10) 权重数高于其他二者, 对生 态环境条件这一评价因子的贡献最大。这与武陵峡地质公园森林覆盖率高, 污染型工业企业 少有关系，优越的自然生态环境为当地生态旅游开发提供了有利条件。与生态旅游资源条件 和生态环境条件相比, 其开发条件 B3 的权重仅为 0.0780 , 说明生态旅游的开发条件 (B3) 是武陵峡地质公园生态旅游发展的制约因素，在其下面的因子评价层中，旅游交通条件 (C15) 的权重（0.5444）明显高于其他各项因子，对地质公园生态旅游开发条件产生决定性影响, 其它基础服务设施、区位条件和客源潜力也会对生态旅游开发的条件产生一定程度影响。

\section{2. 武陵峡公园生态旅游产品开发SWOT分析（P）}

\section{1 优势}

旅游资源优势，旅游资源种类比较齐全，具有明显旅游价值的是神奇的喀斯特峡谷、峰 林、峰从洼地、秀丽的水域风光以及景观形式丰富多样的喀斯特洞穴景观和绚烂多彩的秦巴 风情; 生态环境优势，园区森林覆盖率达到 65\%以上，已经被列入国家级天然林保护区，水 质达到 I 类饮用标准, 空气质量二级标准以上天数达到 $96.4 \%$ 。林海浩瀚、美不胜收; 交通 区位优势, 公园濒临神农架林区, 距离省会城市武汉约 500 公里, 中国卡车之都十堰市、道 教圣地武当山、三峡明珠宜昌市和古隆中襄阳市均在 300 公里之内。

\section{2 劣势}

产品品种单一，体验不足；园道路等级不高，破损严重；景区知名度不高。长期以来人 们都知道竹山是中国绿松石之乡, 女娲补天圣地、古庸国腹地, 相比之下却很少了解这里的 喀斯特山水旅游资源, 在突出其生态资源方面的定位不够准确; 加之武陵峡地质公园作为新 开发的景区，景区建设停留在基础建设阶段，由于资金缺乏，没有通过电视、网络、广播等 多种媒体大力宣传, 影响较小, 制约了景区市场开拓。 


\section{3 机遇}

战略机遇，地处鄂西生态文化旅游圈与十堰 “一城两带”战略布局之中政策优势明显; 交通网络规划; 未来几年，竹山县将紧紧抓住 “竹房城镇带一体化实验区” 和秦巴山片区交 通扶贫的机会, 形成两主两翼、三辐射, 并贯通县内重要旅游景点的交通网络体系; 竹山武 陵峡地质公园的申报与建设正在进行, 借此可以进行内部喀斯特生态资源和管理机构的整合, 使之成为一股合力。

\section{4 威胁}

脆弱的生态环境, 公园所处的喀斯特生态环境是地理环境中一个独特的生态系统, 它有 环境容量低、生态环境系统变异敏感度高, 抗干扰能力弱, 稳定性差; 同质产品的市场竞争 日益突出, 与人文古迹相比, 通常生态旅游产品相互可替代性较强, 尤其是同类型生态旅游 产品更易相互替代。

通过上述 SWOT 分析，竹山武陵峡地质公园生态旅游产品开发方面有较好的资源条件，存 在良好的发展势头和发展机遇，但景区开发还处于初级阶段基础，产品形式单一，且有交通 瓶颈的制约，景区的知名度还不高; 加之周边同质旅游产品的竞争使竹山武陵峡地质公园面 临优势与劣势并存，机遇与威胁同在。因此，合理利用地质公园生态旅游资源，完善景区交 通, 开发特色的旅游产品, 提升地质公园知名度和竞争力成为生态旅游产品开发的重中之重。

\section{3. 竹山武陵峡地质公园生态旅游开发设想与建议}

地质遗迹是地质公园能存在和发展的物质基础，在激烈的旅游市场竞争中，地质遗迹资 源使地质公园有别于其他景区提供的生态旅游产品, 对地质遗迹合理保护利用有利于促进地 质公园旅游的可持续发展。地质公园进行生态旅游开发首先要以保护地质遗迹资源为前提, 在严格限制园区环境容量和对环境质量进行检测的基础之上，进行生态旅游的开发建设，科 学规划、突出特色、区域联动, 以实现地质遗迹的保护和当地经济、社会、生态环境系统以 及当地居民利益等多方面的互利共赢。因此, 竹山武陵峡地质公园生态旅游开发应在保护喀 斯特地质遗迹资源和自然生态环境的前提下，充分挖掘以喀斯特峡谷、溶洞、地质构造剖面、 原始森林和秦巴文化、古庸国文化等高品位的自然和人文生态旅游资源, 努力将武陵峡打造 成集地学科考、科普、生态观光、探险、度假、康乐及文化旅游于一体的国家级地质公园和 国家 $5 \mathrm{~A}$ 级生态旅游风景区, 使其成为湖北旅游的新亮点, 从而促进当地产业结构调整和旅游 业的发展，并通过发展旅游进一步带动本地区社会、经济和环境的全面发展 ${ }^{[5-8]}$ 。

竹山武陵峡地质公园的主题定位 “武陵峡地质公园一一世外桃源武陵峡、我管奇观天台 洞，山水画廊生态园”, 世外桃源武陵峡凸显了武陵峡独特的自然生态风光和奇特的人文遗迹 桃花源, 我管奇观天台洞凸出了天台洞中发现的世界最长的洞穴我管群, “山水画廊生态园” 提出则展现了地质公园主要是以开发生态旅游产品为主; 为突出重点, 武陵峡地质公园的旅 游空间结构的划分可总结为 “一峡, 一镇, 一河, 一洞”, 具体解释为: “一峡” 即武陵峡峡 谷及桃花源风景区，是地质公园核心旅游资源，更是官渡镇旅游发展厚积薄发的总引擎，“一 镇” 即官渡镇，由官渡移民新镇与河西新区共同构成，是官渡镇政治、经济和文化中心，是 反应官渡秦巴民俗风情的核心文化体现区，“一河” 即堵河，在官渡镇境内称之为官渡河，“一 洞” 即天台溶洞; 基于武陵峡地质公园喀斯特生态旅游资源的多样性，以及生态旅游者旅游 需求的多层次性，利用游惒机会图谱的渐变思想，依据资源原始性程度、生态旅游活动对环 境影响的可接受程度及游客在生态旅游活动中的参与性, 可针对不同的消费者群体将地质公 园的生态旅游产品划分为高等级生态旅游产品、中等级生态旅游产品、低等级的生态旅游产 品和泛生态旅游产品四个产品层次 ${ }^{[9-10]}$ 。

在地质公园生态旅游规划和发展过程中通过建立低碳管理系统, 把低碳思想贯穿于地质 公园管理的各个方面, 对地质遗迹资源及其他各种生态资源进行合理开发和保护具有重要作 用。竹山武陵峡地质公园正处于旅游开发的初期, 植被覆盖率高, 生态环境良好, 但与低碳 景区建设相比还有很大的差距，还需要从景区管理的以下几个方面做出努力:（1）实施智能 
化的监测, 更好的把握园区各项环境因子的动态变化规律, 为园区生态保护和合理利用提供 科学依据; (2) 设立 LED 资讯传播平台, 帮助游客深入了解武陵峡地质公园的特点, 引导 游客文明旅游、健康旅游。

建立健全地质公园管理机构，进一步完善基础设施、服务设施、接待设施；加强对旅游 从业者、旅游管理人员、旅游者、社区居民的教育 ${ }^{[11]}$, 培养旅游地学专业人才; 完善财税支 持系统等，有利于竹山武陵峡地质公园的生态旅游可持续发展。

\section{References}

[1] Wei Yuelong, Chen Weihai, Huang Baojian. Geological relics formation mechanism and model of the Leye National Geopark, Guangxi. Acta Geographica Sinica, vol.65, pp.580-594, 2010.

[2] Chen Weihai, Zhu Dehao, Zhu Xuewen etal. Characteristics and evolution of Sanqiao natural bridges karst system in Wulong, Chongqing. Carsologica Sinica, vol.25, pp.99-105, 2006.

[3] Williams P. W. Report on the suitability of Shibing Karst, Guizhou, for inclusion in Phase II the South China Karst World Heritage serial nomination, Sept, 2008.

[4] Wu Bi-hu. An analytic framework of RMP for regional tourism development: case study of Luoyang City. Geographical Research, vol.20, pp.103-110, 2001.

[5] Oliver K. The Role of Ecotourism in Conservation: Panacea or Pandora's box, Biodiversity and Conservation, vol.28, pp. 1-22, 2004.

[6] King A D. Ecotourism and Commodification: Protecting People and Places, Biodiversity and Conservation, vol.5, pp.293-305, 1996.

[7] Campbell M L. Ecotourism in Rural Developing Communities, Annals of Tourism Research, vol.26, pp.534-553, 1999.

[8] David M H. Rezoned for Business: How Eco-Tourism Unlocked Black Farmland in Eastern Zimbabwe, Journal of Agrarian Change, vol.1, pp.575-599, 2001.

[9] Stone W, Jones B L, Wilsenach J, etal. External ecological niche for Candida albicans within reducing, oxygen-limited zones of Wetlands, Applied and environmental microbiology, vol.78, pp.2443-2445, 2012.

[10]Miller E T, Zanne A E, Ricklefsl R E. Niche conservatism constrains Australian honeyeater assemblagesin stressful environments, Ecology Letters, vol.16, pp.1186-1194, 2013.

[11]Robertson, Dawson C, Kuentzel W, etal. College and University Curricula in Ecotourism and Nature-Based Tourism, Journal of Nature Resources and life Sciences Education, vol.25, pp.152-155, 1996. 